Bentham OPEN CrossMark $\quad$ Content list available at: www.benthamopen.com/MEDJ/

EDITORIAL

\title{
Current Concepts and Applications of Technology in Medicine and Surgery: Thoughts, Knowledge and Updates
}

There is little doubt that technology has moved forward dramatically in the last 50 years. Today, it is uncommon for someone not to have a mobile phone and access to the internet. The social impact of this has been greatest, with communication and information access readily available to the majority of people. These two areas are fundamental to the medical profession and so it is not implausible that the influx of technological advances have started to impact on both medical training and careers.

This series aims to look at how technology has influenced medicine over time, highlighting in particular technological advances such as the use of lasers, laparoscopic surgery and more recently robotic assisted procedures. We look at how technology has impacted on medical training both pre- and post- graduation, as well as discussing the growing trend of medical 'apps,' which can influence both the practitioner and the patient. We finish our series by looking at how to use technology optimally, both to treat our patients and publish new advances.

The concept of robots may well have seemed space age and futuristic in the 1960s, but a decade later lasers were first introduced to medicine. Lasers are now being applied in medicine for both diagnostic and therapeutic interventions and their development continues. Jordan et al. take us through the history of the first big development in surgical technology, describing their invention, current uses and what the future may bring.

In 1985, robots were first used to assist surgeons. Since this time, the surgical specialities have promoted the use of technology and the growing trend of robotic assisted surgery has flourished. Reductions in patient hospital stay, operative complications and even the scar size of procedures have promoted their use. $R$ Mafi et al. describe the benefits and areas for further advancement of robotic assisted technology.

With the influx of technology into surgical specialities, there is also a need for education. The technology used is often potentially high risk, particularly when used by the untrained and so simulation of the procedures has now become part of training. Snashall et al. proceed to discuss current training using technology simulation, assessing a standard way of training doctors and surgeons with no risk to patients. Its use, with the advancements in imaging of the human body potentially has an impact on both how we view and interact with the human body.

In particular, our fourth paper looks at how the teaching of anatomy has dramatically changed over time, being closely related to scientific improvements. Jordan et al. next dissect the move from cadaveric study in the $16^{\text {th }}$ century to the use of computer based imaging and the change to self-orientated or problem based learning. The shift towards the latter has led to a perceived suffering of anatomical and pathological knowledge of new doctors and surgeons.

Although the first half of the review focuses more on surgical technology, other articles focus on medical education in general and the use of technology at the bedside.

Snashall et al. both assess and analyse the shift in the delivery of medical education towards e-learning. Specifically, the increased use of smartphone technology and applications (app). They find the use of smart devices and medical apps to be prevalent amongst medical students and predict it will continue to rise in the future. Medical apps may be a very important adjunct in medical education however the evidence remains limited.

Hughes et al. review a similar shift in what has been a mainstay of medical education: bedside teaching. Although bedside teaching has seen a decline over the recent period, it remains a key tool in doctor education. The accessibility of 
medical knowledge on portable devices for both the patient and the doctor should be used to educate both groups at the bedside. In particular the development of apps should be used to supplement and revitalise this teaching method.

Technology has allowed the transfer and publication of information to be easily accessible and available to all. In modern medicine, this has expanded both the number and variety of medical publications and also the way in which the medical profession can access them.

Griffin et al. remind us of the importance of Evidence Based Medicine (EBM). With the number of available sources of information to both the patient and the practitioner, it is vital for the latter to be able to offer and apply the best up to date information to their more medically aware patients.

The ease of access to medical information highlights a greater need for peer reviewed and scientifically sound publications. Mabvuure et al. explain the rationale for publishing, as well as offering practical advice on various types of articles, selecting the destination journal and maximising the visibility of published articles.

With technology now an integral part of modern day life, it has become essential to modern medicine, impacting on how doctors are taught and trained through medical school and into their careers. Technology is now accessible anywhere by both medical professionals and our patients, highlighting the importance of peer reviewed publications and evidence based medicine. We hope to inform our peers of the shift in medical education and help them to be aware so they can keep abreast of the technological advances.

DJ Jordan

Department of Plastic Surgery, Whiston Hospital, Liverpool, UK

E-mail: jord_is@hotmail.com

S Hindocha

Department of Plastic Surgery,

Whiston Hospital,

Liverpool, UK

E-mail: hindocha2001@yahoo.com

(C) Jordan and Hindocha; Licensee Bentham Open

This is an open access article licensed under the terms of the Creative Commons Attribution-Non-Commercial 4.0 International Public License (CC BY-NC 4.0) (https://creativecommons.org/licenses/by-nc/4.0/legalcode), which permits unrestricted, non-commercial use, distribution and reproduction in any medium, provided the work is properly cited. 